\title{
Editorial
}

\section{"Care for the Senior Citizens" in Bangladesh: Present and Future}

HAM NAZMUL AHASAN ${ }^{1}$, CHANDRA SHEKHAR BALA ${ }^{2}$

Bangladesh is a developing country with 149.8 million people living within a relatively small territory. Population density is 1015 per square $\mathrm{km}$ which is highest in the world. ${ }^{1}$ Despite there has been considerable changes in different sectors of life in last two decades. For example annual food productions has increased 6 times than previous andper capita income has raised to 1190 US Dollars. ${ }^{2}$

Population demography is on transition in Bangladesh as well. Life expectancy has risenfrom 49 years to 70 yearsalong with the declining fertility and mortality rates. Approximately $8.4 \%$ of the population is aged over 60 years at present.By 2050 median age may rise to 34.8 yearswith $16 \%$ of its population over the age of 60 years.

Regarding national support \& social security for the elderly: In the past health care system of our country engaged much of its resource, time and energy to combat the communicable diseases and to provide nutrition and improve sanitation. But things have been changed. A recent national level survey revealed that $29 \%$ of the population has two or more risk factors of Non Communicable Diseases. ${ }^{3}$ Medicine wards of medical colleges and other hospitals are dealing with non communicable disease and their complications more than ever. Median age of admission in medicine wards of Dhaka Medical college Hospital was 44.5 years. Based on the facts and figure the Government has taken several measures to ensure health and wellbeing of elderly population.

a) Pension is a monthly retirement incentives to government employees.

b) Age of retirement of Government employee has been increased to 59 years from 57 years.

c) "Old age allowance programme" has been launched in 1998. Under this programme ten elderly people from each ward (each union comprises 9 wards) have been receiving some financial aid although the amount is small

1. Professor of Medicine, Popular Medical College, Dhaka

2. Emergency Medical Officer, National institute of Neurosciences and Hospital, Sher-e-Bangla Nagar Dhaka.

Correspondence: Prof. HAM Nazmul Ahasan, Professor of Medicine, Popular Medical College, Dhaka, E-mail: ahasanhamn@ yahoo.com and inadequate. ${ }^{4}$ Fiveof them must be elderly women. There are 40,950 wards in the rural Bangladesh.

d) The government has adopted a national policy for the senior citizensto ensure dignity, adequate health care and social supports including pension and special saving schemes, reserve seat on bus and trains.

e) Separate programmes for the elderly women, widows and vulnerable group of population are on the move.Very recently a campaign has been launched for the health care for the vulnerable groups which includes special consideration for the elderly.

f) Bangladesh National Assembly has formulated a law on the $27^{\text {th }}$ Oct 2013 that sons and daughters must take care of their parents and grandparents. It would bean offence if they do not do so.

In addition there are many Non Government Organizations working in our country for the elderly people including an old one named Bangladesh Association for the Aged. They run a geriatric hospital in the capital city. The Government and non-government microcredit programmes has improved the ability to purchase as well as social security by increasing the income of the families and by empowering women.

Regarding geriatrics education: Geriatric education is imparted as routine basis to the undergraduate and postgraduate medical education as apart of Internal medicine. There is no postgraduate courses on Geriatric medicine till now. As a result there are lack of expertise and experience prevails in this discipline. There is lack of supporting staffs too.

Regarding the care provided to the elderly: As there is no separate geriatric wing in most of the hospitals and clinics, acute and ambulatory care for the elderly is offered through internists in secondary and tertiary care hospitals.

Last year the first geriatric unit has been launchedin the Dhaka Medical College Hospital.It has 30 beds. Both indoor and limited outdoor service is provided by one associate professor, two assistant professors, one registrar, one assistant registrar and two Indoor medical officers and few senior and junior Staff nurses. The unit is getting appropriate support from all the specialties from time to time. 
Unfortunately long term care for the senior citizens including assisted living and hospice are still to develop in our country as in any low resource setting. Although few in number some old homes are running by both government and nongovernment organizations.

But good news is that still elderly people are loved and honoured inmost of the families. Till date there is a common saying that 'He is lucky who has been born and reared in Japan, has passed his youth in western world and is passing the old age in the Indian subcontinent.' Because fortunately most of the elderly people live with big families and taken care by their children and grand children till date because of strong family and social ties. But things are changing. These traditional values are at risk with the globalization of cultures and lifestyle.The national policy for the elderly people is good and ambitious to some extent. Resource constraint, lack of experience and awareness are pulling back. Government Organizations and Non Government Organizations are working well but not enough to meet the challenge to take care of every elderly of the country.
Senior citizens are the asset of a nation. They have experience, wisdom and knowledge which can be used for the national development and progress. It is the responsibility of every one to take care of them. Old age is an inevitable stage of our life-cycle. We must do everything for the care and comfort of our senior citizens.

\section{References}

1. National Institute of P0opulation Research and Training (NIPORT), Mitra and Associates, and ICF International. 2013. Bangladesh Demographic and Health Survey 2011. Dhaka, Bangladesh and Calverton, Maryland, USA: NIPORT, Mitra and Associates, and ICF International: 2.

2. CPD (2014): State of the Bangladesh Economy in Fiscal Year 2014 (Third Reading): 5.

3. Executive summary, page XXXVII, National NCD risk factor survey 2010 Report.

4. Implementation Manual for Old Age Allowances programme 2013, Ministry of Social Welfare, Government of Bangladesh: 3-5. 